\title{
LEDS COLOURS MIXING USING THEIR SPD AND DEVELOPING OF THE MATHEMATICAL MODEL FOR CCT CALCULATION
}

\author{
Canan PERDAHCI ${ }^{1}$ and Hamdi ÖZKAN ${ }^{2}$ \\ ${ }^{1}$ Department of Electrical Engineering, Faculty of Engineering, University of Kocaeli, Turkey \\ ${ }^{2}$ Litpa Lighting, Koza Plaza, Istanbul, Turkey
}

\begin{abstract}
Light is a condition that human beings are subjected to in nature. Light is not only a physical parameter but also an important factor, which is affecting the mental and cognitive performance of the person. For this reason, in recent years, many researchers and scientists have been working on and exploring this direction of light. The spectral structure of light in the natural environment shows a continuous change. We can define this natural environment as the spectral transformation of daylight in open air. Thus, people who remain in closed environments during the day are living under unfavourable conditions, such as constant colour temperatures and luminous flux of illumination. The studies aimed at reducing this harmful effect the most. These studies are based on the principle that all intermediate colours are obtained by blending the light in 2 different colours (usually one is very warm white and the other is very cold white) and that the intermediate colours are timed within a certain scenario and illuminated indoors to simulate the outside environment. In this study, the mixture of light sources in different colours was mathematically modelled in computer environment and the CCT in $\mathrm{K}$ of the mixture was calculated. It is also optimized to obtain the mixture colour with least mistakes of the mixture functions by comparing with the actual measurement results.
\end{abstract}

Keywords: light emitting diode (LED), spectral power distribution (SPD), correlated colour temperature $(\mathrm{CCT})$

\section{INTRODUCTION}

During the day, the relationship between our biological rhythm and the day's cycle of circulation has led to the emergence of the concept of "Biodynamic Lighting". Biodynamic illumination, which allows people to control the light towards their own desires, can be described as creating a natural lighting environment by following the rhythm of daylight. Thus, the effects of daylight on people are also utilized in working and living spaces. Variable seasons and weather conditions, the day-andnight cycle creates ever-changing light scenarios throughout the day. Therefore, in the biodynamic illumination, the lighting level, colour temperature and light colour vary, not constant. Illumination control systems, such as DALI designed for automation systems or lighting control, and control options provided by these systems can be used to create biodynamic lighting that requires varying levels of illumination or is energy-saving to take advantage of daylight.

Ceiling-recessed LED biodynamic luminaires with dimensions of $600 \mathrm{~mm} \times 600 \mathrm{~mm} \times 120 \mathrm{~mm}$ was designed by LITPA to show the influence of LED biodynamic luminaires with three different lighting scenarios on human performance, Fig.1.

\section{SPECTRAL POWER DISTRIBUTION (SPD)}

This spectral structure of the light rays determines all the characteristics of the light. This is called spectral power distribution (SPD) and pre- 
Table 1. Measuring Data of 2200 K CCT LED \& 7000 K CCT LED

\begin{tabular}{|l|l|l|}
\hline \multicolumn{3}{|c|}{ 2200K LED Measuring Data } \\
\hline WL(nm) & PL & PE(mW/nm) \\
\hline 360 & 0,0059 & 0,2323 \\
\hline 361 & 0,0091 & 0,3548 \\
\hline 362 & 0,0067 & 0,2611 \\
\hline 363 & 0,0074 & 0,2892 \\
\hline 364 & 0,0061 & 0,2387 \\
\hline 365 & 0,0048 & 0,188 \\
\hline 366 & 0,0054 & 0,2124 \\
\hline 367 & 0,0043 & 0,1667 \\
\hline 368 & 0,0023 & 0,0915 \\
\hline 369 & 0,003 & 0,1175 \\
\hline 370 & 0,0044 & 0,1712 \\
\hline & $:$ & \\
\hline & 0,0121 & 0,473 \\
\hline 820 & 0,0113 & 0,4412 \\
\hline 821 & 0,0119 & 0,4681 \\
\hline 822 & 0,0111 & 0,4367 \\
\hline 823 & 0,0107 & 0,4182 \\
\hline 824 & 0,0111 & 0,4365 \\
\hline 825 & 0,01 & 0,3916 \\
\hline 826 & 0,0095 & 0,3706 \\
\hline 827 & 0,0095 & 0,3732 \\
\hline 828 & 0,0095 & 0,3731 \\
\hline 829 & 0,0092 & 0,3624 \\
\hline 830 & & \\
\hline & & \\
\hline
\end{tabular}

sented in Fig. 2 for worm-white and cold-white LED.

The wavelength that the human eye can perceive is usually given in the range of (380-780) $\mathrm{nm}$. Spectral measuring instruments can perform a wider range of measurements. The Everfine HAAS-1200, we use in this study, can measure from 350 to 1000 $\mathrm{nm}$. However, because of $V(\lambda)$, we used range (360 $830) \mathrm{nm}$ in our measurements and calculations. In the spectral chart, the vertical (y) axis is the spectral flux value at each wavelength of the wavelength

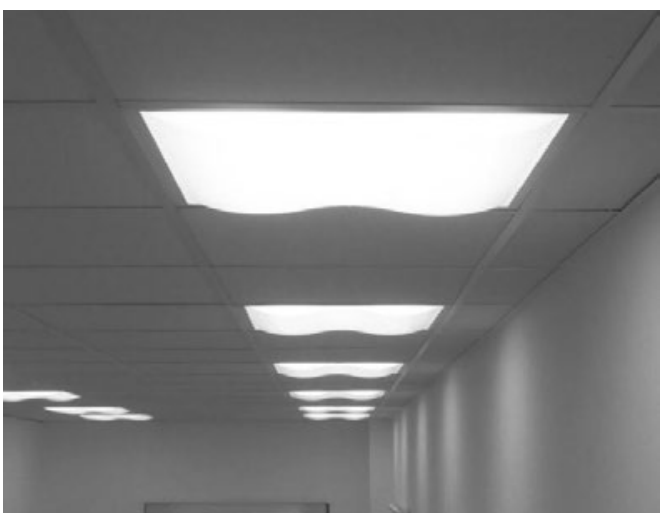

Fig.1. The biodynamic LED luminaire

\begin{tabular}{|l|l|l|}
\hline \multicolumn{3}{|c|}{ 7000K LED Measuring Data } \\
\hline WL(nm) & PL & PE(mW/nm) \\
\hline 360 & 0,0034 & 0,2717 \\
\hline 361 & 0,0048 & 0,3859 \\
\hline 362 & 0,001 & 0,0774 \\
\hline 363 & 0,0041 & 0,3302 \\
\hline 364 & 0,0059 & 0,4741 \\
\hline 365 & 0,0025 & 0,2034 \\
\hline 366 & 0,0047 & 0,375 \\
\hline 367 & 0,0037 & 0,2945 \\
\hline 368 & 0,0031 & 0,2512 \\
\hline 369 & 0,0045 & 0,3584 \\
\hline 370 & 0,0041 & 0,3314 \\
\hline & $:$ & \\
\hline 820 & 0,0017 & 0,136 \\
\hline 821 & 0,0022 & 0,1753 \\
\hline 822 & 0,0017 & 0,1338 \\
\hline 823 & 0,0019 & 0,1505 \\
\hline 824 & 0,002 & 0,1602 \\
\hline 825 & 0,0013 & 0,1018 \\
\hline 826 & 0,0018 & 0,1456 \\
\hline 827 & 0,0015 & 0,1204 \\
\hline 828 & 0,0015 & 0,1197 \\
\hline 829 & 0,0015 & 0,1174 \\
\hline 830 & 0,0016 & 0,1303 \\
\hline & & \\
\hline
\end{tabular}

range. We measure this value by the spectroradiometric device in $[\mathrm{mW} / \mathrm{nm}]$.

\section{LABORATORY MEASUREMENTS}

Our laboratory measurements consist of two steps. In the first step, we can calculate the spectral power distribution data of the radiation in two different light colours. In the second stage, it was done to find out, which currents of intermediate colours were obtained by driving both colour LEDs at different driving currents and to verify and optimize the calculations according to these measurements.

\subsection{Luminaire used in Measurements}

The luminaires used in the measurements are Biodynamic and are made with LEDs of both colours at $2200 \mathrm{~K}$ and $7000 \mathrm{~K}$ CCT values. In addition, the driver output currents can be programmed via the DALI interface by dimming at desired dim levels. There are 90 pieces of 2200 K LEDs and 90 pieces of $7000 \mathrm{~K}$ LEDs in the luminaire. LED chips are placed next to each other in order to optimize 
Table 2. Meaning of Terms Used in Equation 1

\begin{tabular}{|c|c|}
\hline$\lambda$ & $\begin{array}{c}\text { A series from } 360 \mathrm{~nm} \text { to } 830 \mathrm{~nm} \\
\text { (If we take the starting value } 0 \text {, a series } \\
\text { of up to } 470)\end{array}$ \\
\hline$W(\lambda)$ & $(\mathrm{mW} / \mathrm{nm})$ Warm White SPD data \\
\hline$C(\lambda)$ & $(\mathrm{mW} / \mathrm{nm})$ Cold White SPD data \\
\hline$M(\lambda)$ & $(\mathrm{mW} / \mathrm{nm})$ Mixed SPD data \\
\hline
\end{tabular}

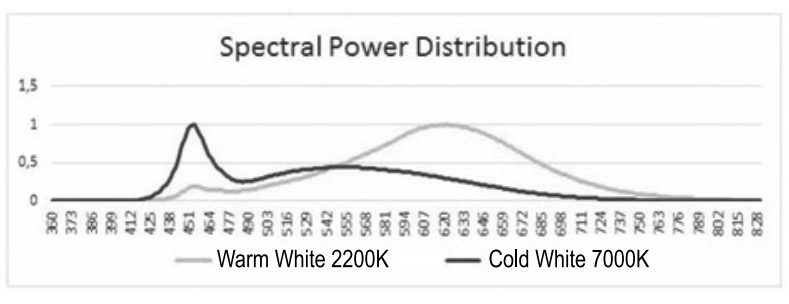

Fig. 2. LEDs Spectral Power Distribution

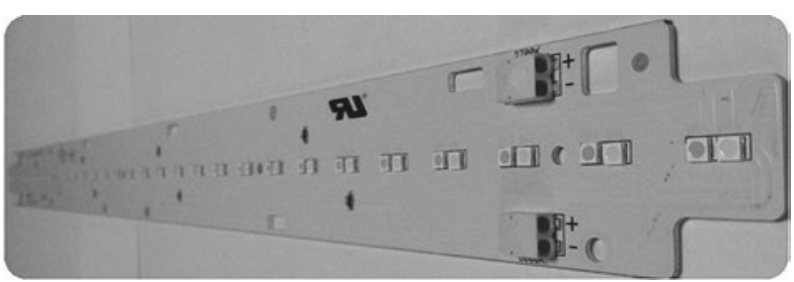

Fig.3. PCB of Biodynamic LED luminaire

the colours (Fig. 3) and a special diffuser (Fig. 4) is used in the luminaire;

90 units of $2200 \mathrm{~K}$ LEDs are the $1^{\text {st }}$ group with its own driver. The other 90 LEDs are $7000 \mathrm{~K}$ and this $2^{\text {nd }}$ group of LEDs is also driven by a $2^{\text {nd }}$ driver. Both groups have a maximum $500 \mathrm{~mA}$ driving current. Output currents in the range of 0 to $500 \mathrm{~mA}$ are obtained by dimming via DALI protocol or completely turning OFF the drivers. Linear dimming is used as a method of dimming in operation. When $50 \%$ dimming is done, $250 \mathrm{~mA}$ value of max current of $50 \%$ will be taken as output current. Each of the 90 LED circuits in two groups consists of 6 serial 5 parallel circuit connections. Thus, when the driver is supplied with $500 \mathrm{~mA}$, an LED is driven with $100 \mathrm{~mA}$. The dimming ratio from 0 to 100 on the DALI means to drive the LED from 0 to 100 mA current.

\subsection{Experimental Study}

In two-stage measurements, the dim ratio of $2200 \mathrm{~K}$ LEDs in 1 step is set to $100 \%, 7000 \mathrm{~K}$ LEDs are turned OFF and the spectral data is taken.
In the same way, the dimming rate of $7000 \mathrm{~K}$ LEDs is adjusted to $100 \%$ and $2200 \mathrm{~K}$ LEDs are turned on OFF position, and the spectral data of $7000 \mathrm{~K}$ LEDs are also taken (Table 1).

\section{MATHEMATICAL MODEL OF COLOUR MIX}

The spectral data are of two types and the first type is the amount of energy flux possessed per wavelength. These sizes constitute the characteristic of the light colour. The second type is the case where the energy value of the wavelength having the maximum value in the collection of these energy values is taken as 1 and the energy values of the other wavelengths are normalized by proportioning accordingly (Figs. 4-5). We can say, the normalization coefficient to the energy value of the maximum value. The normalization coefficient is a special value that is unique to the light source to which it is concerned. Each light source, each different colour and each light form has its own specific normalization coefficient. Therefore, when calculating the mixture colour, we must use the first type data and go through the actual energy values.

To calculate the colour that will result in a colour mixture result, we sum the spectral data of each of the two ranks. In other words, we create the mixture

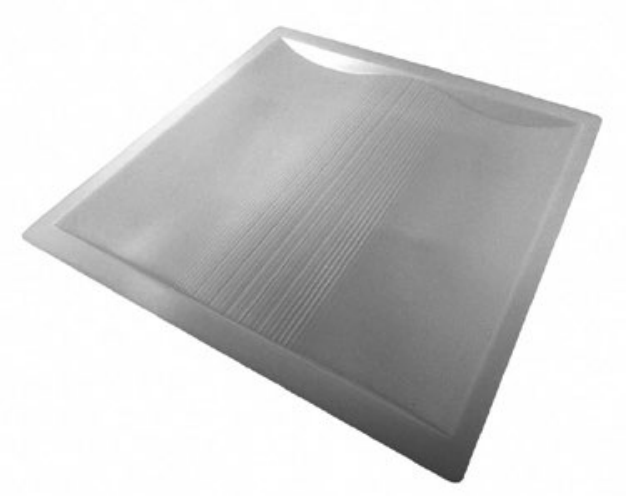

Fig.4. Special diffuser of Biodynamic LED luminaire 


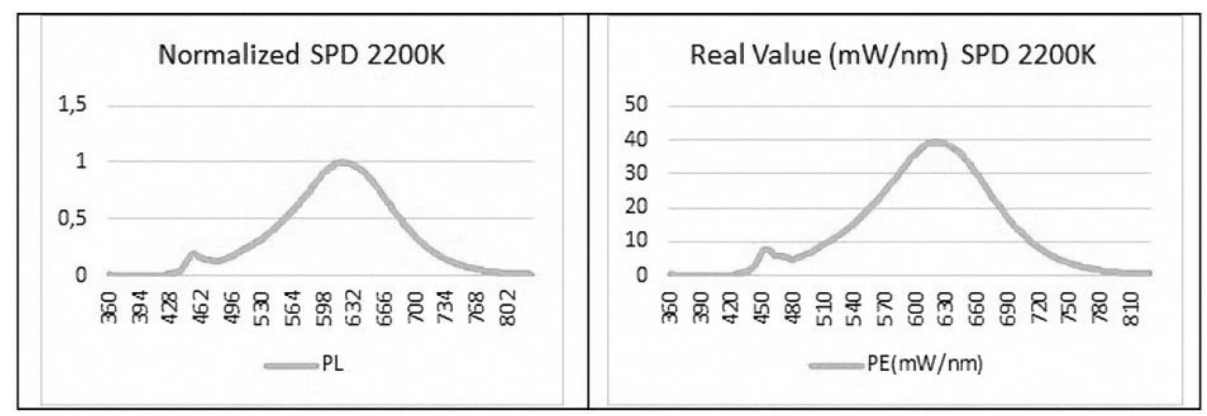

Fig.5. SPD of Light Source at CCT $2200 \mathrm{~K}$

colour by summing the real luminous values of the same wavelengths (Equation 1);

$$
M(\lambda)=W(\lambda)+C(\lambda) .
$$

\subsection{Colour Matching Functions}

To calculate the CCT values of the colours from the spectral diagram data, we need three main colour spectral value tables. These values are defined in CIE1931 as $2^{\circ}$ colour equalization functions. (Colour-matching functions for CIE2 ${ }^{\circ}$ Standard Observer (1931)) [1].

Among the colours, red, green, and blue colours are generally regarded as the three main colours of light. The reason for this is that our eyes are sensitive to these three primary colours and the eye contains three types of cones (colour sensors) that are sensitive and allow colour perception. According to the 1931 Standard Observer's definition of CIE [1], Fig. 9 shows spectral sensitivity curves corresponding to the human eye. These are called colour matching functions. It has a high sensitivity in the red, green and blue wavelength regions.

\subsection{Calculation of Tristimulus Values}

Tristimulus values, which are determined based on colour matching functions and defined by the CIE in 1931, are also referred to as $2^{\circ} \mathrm{XYZ}$ tristimulus values. When evaluating the brightness of the colours relative to each other, people see the light in the green parts of the spectrum brighter than the red or blue light of equal power. For this reason, we take the $Y$ value representing green light as 100 and form the $K$ coefficient and the reduced tristumulus values for $X$ and $Z$. [3], see also Table 3 .

Calculation of the Tristimulus values using the colour matching functions for CCT $2200 \mathrm{~K}$ :

$$
\begin{gathered}
X 1=K 1 \times \int_{360}^{830} W(\lambda) \times \bar{X}(\lambda) \times R(\lambda) \times d \lambda . \\
Y 1=K 1 \times \int_{360}^{830} W(\lambda) \times \bar{Y}(\lambda) \times R(\lambda) \times d \lambda . \\
Z 1=K 1 \times \int_{360}^{830} W(\lambda) \times \bar{Z}(\lambda) \times R(\lambda) \times d \lambda . \\
K 1=\frac{100}{\int_{360}^{830} W(\lambda) \times \bar{Y}(\lambda) \times R(\lambda) \times d \lambda} .
\end{gathered}
$$

Calculation of the Tristimulus values using the colour matching functions for $7000 \mathrm{~K}$ :

$$
\begin{gathered}
X 2=K 2 \times \int_{360}^{830} C(\lambda) \times \bar{X}(\lambda) \times R(\lambda) \times d \lambda . \\
Y 2=K 2 \times \int_{360}^{830} C(\lambda) \times \bar{Y}(\lambda) \times R(\lambda) \times d \lambda . \\
Z 2=K 2 \times \int_{360}^{830} C(\lambda) \times \bar{Z}(\lambda) \times R(\lambda) \times d \lambda . \\
K 2=\frac{100}{\int_{360}^{830} C(\lambda) \times \bar{Y}(\lambda) \times R(\lambda) \times d \lambda} .
\end{gathered}
$$

We calculate the tristimulus values using the matching functions for the mixture colour:

$$
\begin{aligned}
& X 3=K 3 \times \int_{360}^{830} M(\lambda) \times \bar{X}(\lambda) \times R(\lambda) \times d \lambda . \\
& Y 3=K 3 \times \int_{360}^{830} M(\lambda) \times \bar{Y}(\lambda) \times R(\lambda) \times d \lambda .
\end{aligned}
$$


Table 3. Meaning of Terms Used in Formulas

\begin{tabular}{|c|c|}
\hline$\lambda$ & Wavelength (array with increment 1 from $360 \mathrm{~nm}$ to $830 \mathrm{~nm}$ ) \\
\hline$W(\lambda)$ & SPD for $2200 \mathrm{~K}$ \\
\hline$c(\lambda)$ & SPD for $7000 \mathrm{~K}$ \\
\hline$M(\lambda)$ & SPD for mixture \\
\hline $\bar{X}(\lambda)$ & CIE1931 standard observer colour equalization function (for Red Main Colour) \\
\hline $\bar{Y}(\lambda)$ & CIE1931 standard observer colour equalization function (for Green Main Colour) \\
\hline $\bar{Z}(\lambda)$ & CIE1931 standard observer colour equalization function (for Blue Main Colour) \\
\hline$R(\lambda)$ & Spectral reflectance ratio (We assume as 1 ) \\
\hline $\mathrm{K} 1, \mathrm{~K} 2, \mathrm{~K} 3$ & Reduction coefficient (Calculated based on $Y=100$ ) \\
\hline $\mathrm{X} 1, \mathrm{Y} 1, \mathrm{Z} 1$ & Tristimulus values for $2200 \mathrm{~K}$ \\
\hline $\mathrm{X} 2, \mathrm{Y} 2, \mathrm{Z2}$ & Tristimulus values for $7000 \mathrm{~K}$ \\
\hline$X 3, Y 3, Z 3$ & Tristimulus values for mixture \\
\hline $\mathrm{X} 1 T, \mathrm{Y} 1_{T}, \mathrm{Z1}{ }_{T}$ & Reduced tristimulus values relative to $\mathrm{Y} 1=100$ for $2200 \mathrm{~K}$ \\
\hline$X 2 T, Y 2 T, Z 2 T$ & Reduced tristimulus values relative to $\mathrm{Y} 2=100$ for $7000 \mathrm{~K}$ \\
\hline $\mathrm{X} 3 \mathrm{~T}, \mathrm{Y} 3 \mathrm{~T}, \mathrm{Z} \mathrm{T}$ & Reduced tristimulus values relative to $Y 3=100$ for Mixture \\
\hline $\mathrm{X} 1 \mathrm{x}, \mathrm{Y} 1 \mathrm{y}$ & Tristimulus values for $2200 \mathrm{~K}$ \\
\hline $\bar{X} 2 x, Y 2 y$ & Tristimulus values for $7000 \mathrm{~K}$ \\
\hline$X 3 x, Y 3 y$ & Tristimulus values for mixture \\
\hline
\end{tabular}

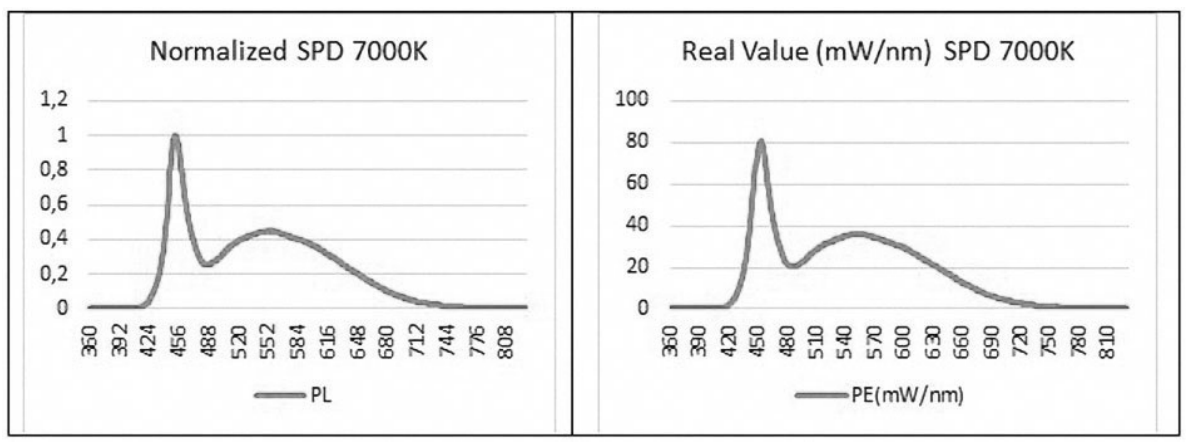

Fig. 6. SPD of Light Source at CCT $7000 \mathrm{~K}$

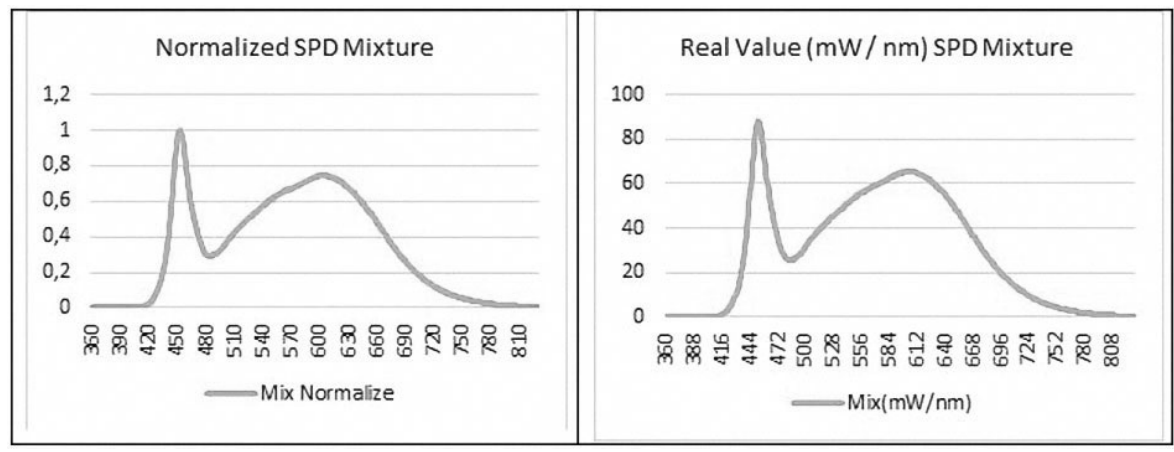

Fig.7. SPD of Mixed Light Source

$Z 3=K 3 \times \int_{360}^{830} M(\lambda) \times \bar{Z}(\lambda) \times R(\lambda) \times d \lambda$.

$$
K 3=\frac{100}{\int_{360}^{830} M(\lambda) \times \bar{Y}(\lambda) \times R(\lambda) \times d \lambda} .
$$

\subsection{Calculation of Chromaticity Coordinates}

The chromaticity coordinates $(x, y)$ are based on standard tristimulus (XYZ) values. These standards have been established by (CIE) [3]. From the obtained tristimulus values, we calculate the $x$ and $y$ coordinates of the light colour in CIE1931 colour space with the following formulas; 


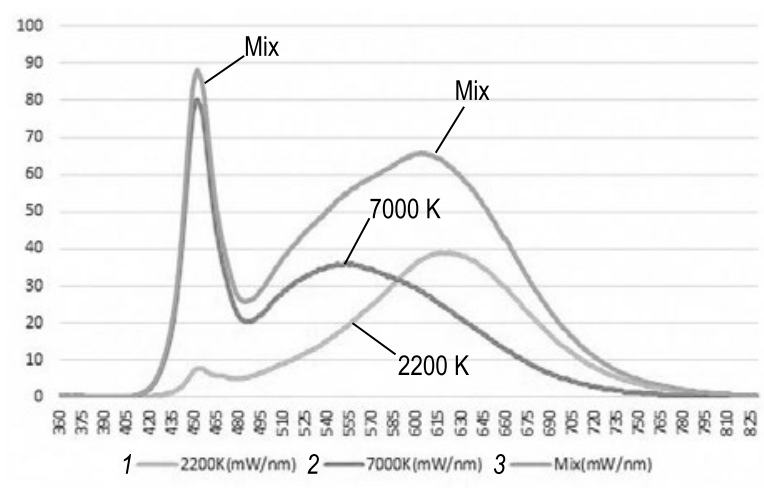

Fig.8. CCT 2200K and CCT 7000K, and their SPD data mixture

$$
\begin{aligned}
& x=\frac{X}{(X+Y+Z)} . \\
& y=\frac{Y}{(X+Y+Z)} .
\end{aligned}
$$

\subsection{Calculation of CCT}

Using the McCamy formula [4], calculate the $\mathrm{CCT}$ values in Kelvin using the $x$ and $y$ coordinates:

$$
\begin{gathered}
N=\frac{(x-0.33320)}{(0.1858-y)} . \\
C C T=449 \times N^{3}+3525 \times N^{2}+ \\
+68253.3 \times N+5520.33 .
\end{gathered}
$$

\section{VERIFICATION OF MEASURED VALUES IN THE EXPERIMENT}

First we calculate the tristimulus values using the spectral data, then we calculate the chromaticity coordinates, finally we calculate the CCT (Fig. 10).

We calculate the tristimulus values using the SPD data for the $W(\lambda)$ sequence measured for 2200 $\mathrm{K}$ CCT with taking into account Equations 2,3,4,5.

$$
\begin{gathered}
X 1=\sum_{\lambda=360}^{830} \bar{X}(\lambda) W(\lambda), Y 1=\sum_{\lambda=360}^{830} \bar{Y}(\lambda) W(\lambda), \\
Z 1=\sum_{\lambda=360}^{830} \bar{Z}(\lambda) W(\lambda), \\
K 1=\frac{100}{Y 1}
\end{gathered}
$$

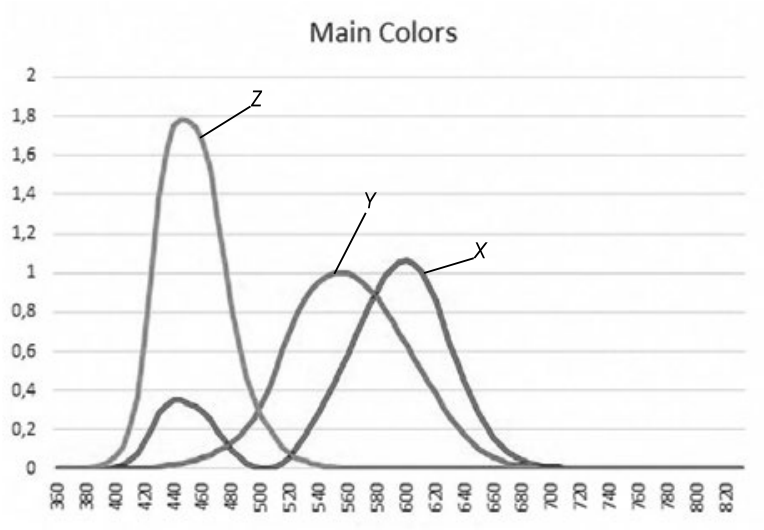

Fig.9. $\mathrm{X}_{\mathrm{Y}} \overline{\mathrm{Z}}^{-}$colour matching functions

$X 1_{T}=K 1 \times X 1 Y 1_{T}=K 1 \times Y 1 Z 1_{T}=K 1 \times Z 1$.

Chromaticity coordinates for $2200 \mathrm{~K}$ CCT have been calculated based on Equations 14 \& 15;

$$
\begin{gathered}
X 1_{X}=\frac{X 1_{T}}{X 1_{T}+Y 1_{T}+Z 1_{T}}, \\
Y 1_{Y}=\frac{Y 1_{T}}{X 1_{T}+Y 1_{T}+Z 1_{T}} .
\end{gathered}
$$

CCT calculation for $2200 \mathrm{~K}$ has been performed based on Equations 16 \& 17;

$$
\begin{gathered}
N 1=\frac{X 1_{X}-0.332}{0.1858-Y 1_{Y}} \\
C C T 1=449 \times N 1^{3}+3525 \times N 1^{2}+ \\
+6823.3 \times N 1+5520.33 .
\end{gathered}
$$

$C C T 1=2260 \mathrm{~K}$ (The measured value by the device is $2277 \mathrm{~K}$, difference rate is the $0.7465 \%$ )

We calculate the tristimulus values using the SPD data for the $C(\lambda)$ sequence measured at $7000 \mathrm{~K}$ based on Equations 6,7,8,9:

$$
\begin{gathered}
X 2=\sum_{\lambda=360}^{830} \bar{X}(\lambda) C(\lambda), Y 2=\sum_{\lambda=360}^{830} \bar{Y}(\lambda) C(\lambda), \\
Z 2=\sum_{\lambda=360}^{830} \bar{Z}(\lambda) C(\lambda) . \\
K 2=\frac{100}{Y 2} \\
X 2_{T}=K 2 \times X 2, Y 2_{T}=K 2 \times Y 2,
\end{gathered}
$$




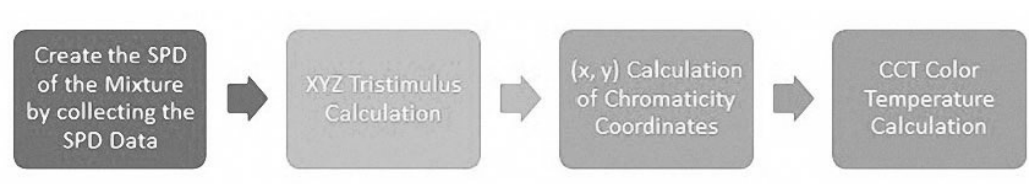

Fig. 10. Flow chart of Verification of Measured Values

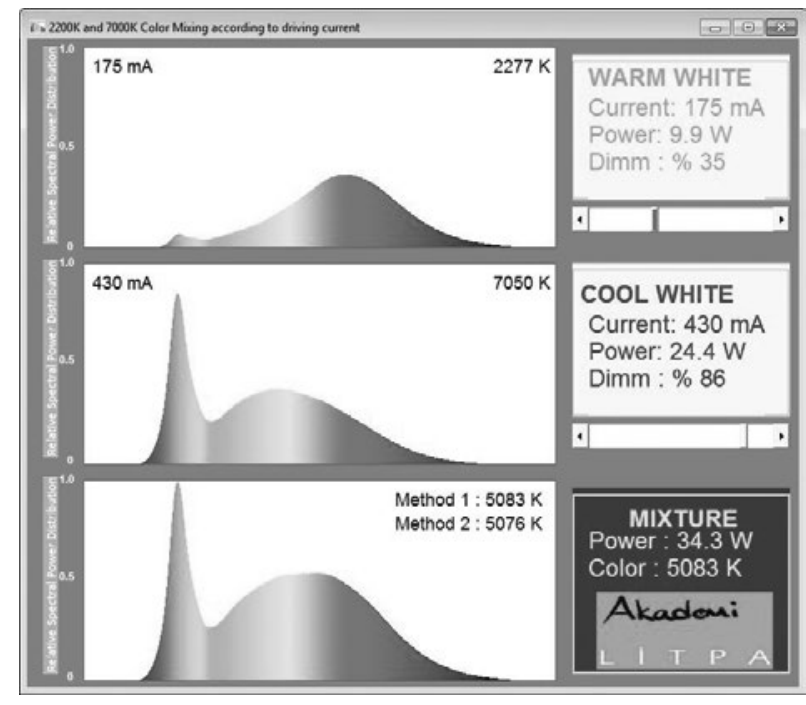

Fig.11. Screenshot of the Software

$$
Z 2_{T}=K 2 \times Z 2
$$

Chromaticity coordinates for CCT $7000 \mathrm{~K}$ have been calculated based on Equations 14 \& 15;

$$
\begin{aligned}
& X 2_{X}=\frac{X 2_{T}}{X 2_{T}+Y 2_{T}+Z 2_{T}}, \\
& Y 2_{Y}=\frac{Y 2_{T}}{X 2_{T}+Y 2_{T}+Z 2_{T}} .
\end{aligned}
$$

CCT calculation for $7000 \mathrm{~K}$ is based on Equations $16 \& 17$;

$$
\begin{gathered}
N 2=\frac{X 2_{X}-0.332}{0.1858-Y 2_{Y}} \\
C C T 2=449 \times N 2^{3}+3525 \times N 2^{2}+ \\
+6823.3 \times N 2+5520.33
\end{gathered}
$$

$C C T 2=7049 K \quad$ (The measured value by the device is $7052 \mathrm{~K}$, difference rate is the $0.0425 \%$ )

We first calculate the tristimulus values for the mixture colour using the $M(\lambda)$ sequence (SPD Data) calculated by Equation 1 based on Equations 10,11,12,13:

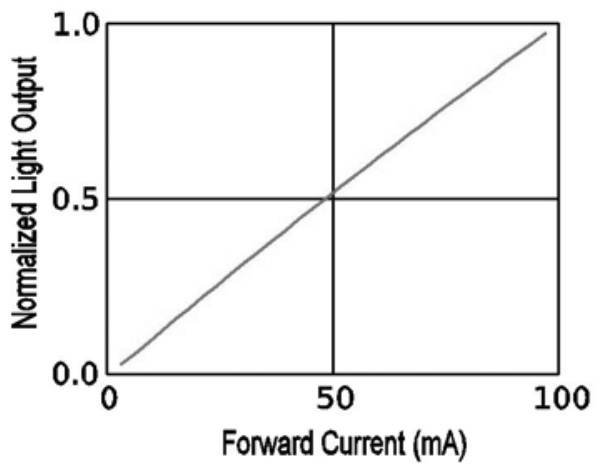

Fig. 12. Current vs. light output diagram

$$
\begin{gathered}
X 3=\sum_{\lambda=360}^{830} \bar{X}(\lambda) M(\lambda), Y 3=\sum_{\lambda=360}^{830} \bar{Y}(\lambda) M(\lambda), \\
Z 3=\sum_{\lambda=360}^{830} \bar{Z}(\lambda) M(\lambda) . \\
K 3=\frac{100}{Y 3} \\
X 3_{T}=K 3 \times X 3, Y 3_{T}=K 3 \times Y 3, \\
Z 3_{T}=K 3 \times Z 3 .
\end{gathered}
$$

Chromaticity coordinates of colour mixture were calculated based on Equations 14 \& 15:

$$
\begin{gathered}
X 3_{X}=\frac{X 3_{T}}{X 3_{T}+Y 3_{T}+Z 3_{T}}, \\
Y 3_{Y}=\frac{Y 3_{T}}{X 3_{T}+Y 3_{T}+Z 3_{T}} .
\end{gathered}
$$

CCT calculation for Colours Mixture were calculated based on Equations 16 \& 17:

$$
N 3=\frac{X 3_{X}-0.332}{0.1858-Y 3_{Y}}
$$

$$
\begin{gathered}
C C T_{M I X}=449 \times N 3^{3}+3525 \times N 3^{2}+ \\
+6823.3 \times N 3+5520.33 .
\end{gathered}
$$

$C C T_{M I X}=4042 K$ (The measured value by the measurement device is the $4033 \mathrm{~K}$, difference rate is the $0.0425 \%$ ) 
Table 4. Comparison of Laboratory Measurement Data with Mathematical Model

\begin{tabular}{|c|c|c|c|c|c|c|c|c|}
\hline \multicolumn{2}{|c|}{ Dim ratings, $\%$} & \multicolumn{2}{|c|}{ Current, mA } & \multirow{2}{*}{$\begin{array}{c}\text { Measured } \\
\text { CCT, K }\end{array}$} & \multirow{2}{*}{$\begin{array}{l}\text { Mathematical } \\
\text { model, } \mathbf{K}\end{array}$} & \multirow{2}{*}{$\begin{array}{l}\text { Difference } \\
\text { rate, } \%\end{array}$} & \multirow{2}{*}{$\begin{array}{c}\text { Optimized } \\
\text { mathematical } \\
\text { model, } K\end{array}$} & \multirow{2}{*}{$\begin{array}{c}\text { Difference } \\
\text { rate, \% }\end{array}$} \\
\hline $7000 \mathrm{~K}$ & $2200 \mathrm{~K}$ & $7000 \mathrm{~K}$ & $2200 \mathrm{~K}$ & & & & & \\
\hline 100 & 0 & 500 & 0 & 7052 & 7050 & $-0,028$ & 7071 & 0,27 \\
\hline 100 & 10 & 500 & 50 & 6378 & 6356 & $-0,345$ & 6356 & $-0,35$ \\
\hline 100 & 20 & 500 & 101 & 5839 & 5898 & 1,01 & 5817 & $-0,38$ \\
\hline 100 & 30 & 500 & 151 & 5428 & 5496 & 1,25 & 5411 & $-0,31$ \\
\hline 100 & 40 & 500 & 199 & 5112 & 5178 & 1,29 & 5101 & $-0,22$ \\
\hline 100 & 50 & 500 & 247 & 4860 & 4911 & 1,05 & 4849 & $-0,226$ \\
\hline 100 & 60 & 500 & 300 & 4624 & 4664 & 0,87 & 4623 & $-0,022$ \\
\hline 100 & 70 & 500 & 351 & 4432 & 4463 & 0,699 & 4433 & 0,023 \\
\hline 100 & 80 & 500 & 402 & 4272 & 4290 & 0,42 & 4274 & 0,045 \\
\hline 100 & 90 & 500 & 449 & 4149 & 4152 & 0,072 & 4146 & $-0,072$ \\
\hline 100 & 100 & 500 & 500 & 4033 & 4021 & $-0,298$ & 4021 & $-0,297$ \\
\hline 90 & 100 & 448 & 500 & 3913 & 3891 & $-0,562$ & 3898 & $-0,38$ \\
\hline 80 & 100 & 401 & 500 & 3798 & 3765 & $-0,87$ & 3780 & $-0,47$ \\
\hline 70 & 100 & 350 & 500 & 3661 & 3619 & $-1,15$ & 3643 & $-0,49$ \\
\hline 60 & 100 & 297 & 500 & 3505 & 3455 & $-1,4$ & 3489 & $-0,456$ \\
\hline 50 & 100 & 252 & 500 & 3361 & 3305 & $-1,67$ & 3347 & $-0,417$ \\
\hline 40 & 100 & 198 & 500 & 3164 & 3113 & $-1,61$ & 3160 & $-0,126$ \\
\hline 30 & 100 & 150 & 500 & 2985 & 2930 & $-1,84$ & 2977 & $-0,268$ \\
\hline 20 & 100 & 100 & 500 & 2766 & 2727 & $-1,41$ & 2765 & $-0,036$ \\
\hline 10 & 100 & 52 & 500 & 2540 & 2518 & $-0,87$ & 2541 & 0,0394 \\
\hline 0 & 100 & 0 & 500 & 2277 & 2277 & 0 & 2270 & $-0,307$ \\
\hline 10 & 10 & 52 & 52 & 4062 & 4021 & $-1,01$ & 4021 & $-1,01$ \\
\hline 20 & 20 & 101 & 101 & 4021 & 4021 & 0 & 4021 & 0 \\
\hline 30 & 30 & 151 & 151 & 4021 & 4021 & 0 & 4021 & 0 \\
\hline 40 & 40 & 199 & 199 & 4019 & 4021 & 0,0497 & 4021 & 0,05 \\
\hline 50 & 50 & 253 & 253 & 4019 & 4021 & 0,0497 & 4021 & 0,05 \\
\hline 60 & 60 & 298 & 298 & 4021 & 4021 & 0 & 4021 & 0 \\
\hline 70 & 70 & 352 & 351 & 4026 & 4024 & $-0,0497$ & 4024 & $-0,05$ \\
\hline 80 & 80 & 404 & 403 & 4026 & 4024 & $-0,0497$ & 4024 & $-0,05$ \\
\hline 90 & 90 & 452 & 449 & 4028 & 4029 & 0,025 & 4013 & $-0,37$ \\
\hline 100 & 100 & 500 & 500 & 4033 & 4021 & $-0,297$ & 4021 & $-0,298$ \\
\hline 50 & 100 & 255 & 500 & 3362 & 3315 & $-1,398$ & 3357 & $-0,149$ \\
\hline 50 & 90 & 255 & 449 & 3453 & 3412 & $-1,187$ & 3452 & $-0,029$ \\
\hline 50 & 80 & 256 & 402 & 3549 & 3522 & $-0,761$ & 3557 & 0,225 \\
\hline 50 & 70 & 257 & 351 & 3678 & 3666 & $-0,33$ & 3692 & 0,38 \\
\hline
\end{tabular}




\begin{tabular}{|c|c|c|c|c|c|c|c|c|}
\hline \multicolumn{2}{|c|}{ Dim ratings, $\%$} & \multicolumn{2}{|c|}{ Current, mA } & \multirow{2}{*}{$\begin{array}{c}\text { Measured } \\
\text { CCT, K }\end{array}$} & \multirow{2}{*}{$\begin{array}{l}\text { Mathematical } \\
\text { model, } \mathbf{K}\end{array}$} & \multirow{2}{*}{$\begin{array}{l}\text { Difference } \\
\text { rate, } \%\end{array}$} & \multirow{2}{*}{$\begin{array}{l}\text { Optimized } \\
\text { mathematical } \\
\text { model, } \mathbf{K}\end{array}$} & \multirow{2}{*}{$\begin{array}{l}\text { Difference } \\
\text { rate, \% }\end{array}$} \\
\hline $7000 \mathrm{~K}$ & $2200 \mathrm{~K}$ & $7000 \mathrm{~K}$ & $2200 \mathrm{~K}$ & & & & & \\
\hline 50 & 60 & 257 & 298 & 3846 & 3847 & 0,026 & 3860 & 0,36 \\
\hline 50 & 50 & 257 & 253 & 4021 & 4040 & 0,47 & 4039 & 0,448 \\
\hline 50 & 40 & 257 & 199 & 4306 & 4338 & 0,74 & 4317 & 0,255 \\
\hline 50 & 30 & 257 & 151 & 4644 & 4691 & 1,01 & 4653 & 0,19 \\
\hline 50 & 20 & 257 & 101 & 5149 & 5193 & 0,85 & 5143 & $-0,117$ \\
\hline 50 & 10 & 257 & 53 & 5850 & 5880 & 0,51 & 5837 & $-0,22$ \\
\hline 50 & 0 & 257 & 0 & 7021 & 7050 & 0,41 & 7090 & 0,98 \\
\hline 0 & 50 & 0 & 254 & 2274 & 2277 & 0,13 & 2264 & $-0,44$ \\
\hline 10 & 50 & 53 & 253 & 2753 & 2747 & $-0,218$ & 2766 & 0,47 \\
\hline 20 & 50 & 103 & 253 & 3137 & 3133 & $-0,127$ & 3164 & 0,86 \\
\hline 30 & 50 & 154 & 254 & 3482 & 3474 & $-0,23$ & 3501 & 0,55 \\
\hline 40 & 50 & 203 & 254 & 3754 & 3762 & 0,21 & 3777 & 0,61 \\
\hline 50 & 50 & 257 & 253 & 4021 & 4040 & 0,47 & 4039 & 0,448 \\
\hline 60 & 50 & 304 & 254 & 4206 & 4242 & 0,86 & 4230 & 0,57 \\
\hline 70 & 50 & 359 & 254 & 4400 & 4453 & 1,20 & 4419 & 0,43 \\
\hline 80 & 50 & 410 & 254 & 4561 & 4623 & 1,36 & 4576 & 0,33 \\
\hline 90 & 50 & 458 & 254 & 4691 & 4765 & 1,58 & 4709 & 0,38 \\
\hline 100 & 50 & 500 & 247 & 4860 & 4911 & 1,049 & 4849 & $-0,226$ \\
\hline
\end{tabular}

\section{SOFTWARE THAT CALCULATES MIXTURE VALUES FOR DIFFERENT DIM RATIOS}

By using these two data at hand, we calculated the colour of the mixture when mixing $100 \%$ of both colors, using only the warm white spectral data and the cold white spectral data. So, to calculate what the mixture will be at different mixing ratios, we calculate the mixture after mixing the two SPD values of the two colours with the dim ratio in $\%$.

Our new mixture formula is as follows:

$$
M(\lambda)=\operatorname{Dim} 1 \times W(\lambda)+\operatorname{Dim} 2 \times C(\lambda) .
$$

With this software spectral data of CCT $2200 \mathrm{~K}$ LED and spectral data of CCT $7000 \mathrm{~K}$ LED are visualized, and the mixture colour is calculated by two different methods depending on the desired dim ratio. For the representation of the spectral data, the values are normalized by assuming a maximum va- lue of 1 , which is the value of the sequence, and the spectrum chart is formed in this way. The dim ratio determined by the scrolling bars of both colours enlarges the spectral ratio from 0 to 100 as a multiplier of the spectral power values at all wavelengths between $360 \mathrm{~nm}$ and $830 \mathrm{~nm}$. This change affects the spectral data sequence with a maximum value of 1 in proportionately. The sum of the two colours is calculated based on the dim ratio and the spectral data of the mixture is displayed simultaneously. Two different calculation methods are used in this software. First method is the McCamy method, which is the calculation method we use in our article. The second method is the CIECAM02 based calculation method. This calculation method will not be examined in this article.

\section{LABORATORY MEASUREMENTS AND VERIFICATION}

All intermediate values can be calculated with the software. A number of laboratory measurements 


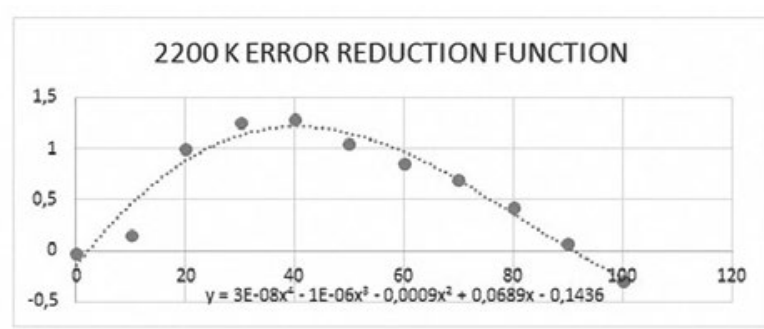

Fig. 13. Difference reduction function diagram for $2200 \mathrm{~K} \mathrm{CCT}$

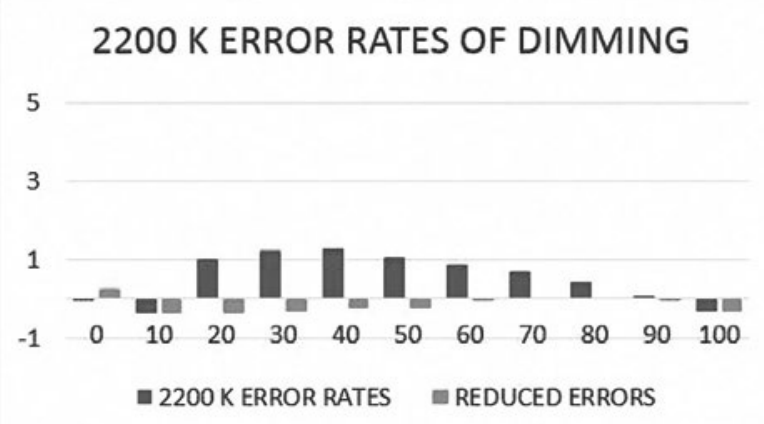

Fig. 15. CCT $2200 \mathrm{~K}$ difference rates in dependence of dimming

are needed to verify the mathematical model. For the verification of calculations and software outputs, laboratory measurements were made at the following dim ratios and the deviation ratios were determined by comparing, Table 4 .

\section{IMPROVING DIFFERENCE REDUCTION FUNCTION AND RE-VERIFYING BY APPLYING TO CALCULATIONS}

Calculated values show up to $1.5 \%$ deviations. The regions where these deviations are generated are those where one of the colours is at the maximum level, while the other colour is at $30 \%, 40 \%$, $50 \%, 60 \%$ dim levels. This is because the variation of the luminous flux of the LED is not directly proportional to the dim levels. We can see this clearly in the graph of luminous flux change according to the dim levels given in the LED datasheet.

Fig. 13 shows the difference ratios for $2200 \mathrm{~K}$ LEDs from $0 \%$ to $100 \%$ for each dim level with $10 \%$ increase when the $7000 \mathrm{~K}$ LED is at $100 \% \mathrm{dim}$. From this graph $\mathrm{y}=3 \mathrm{E}-08 \times 4-1 \mathrm{E}-06 \times 3$ $0,0009 x 2+0,0689 x-0,1436$ difference reduction function is obtained.

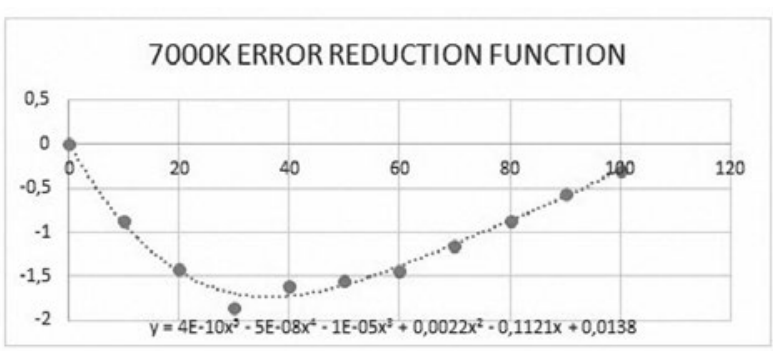

Fig. 14. Difference reduction function diagram for CCT $7000 \mathrm{~K}$

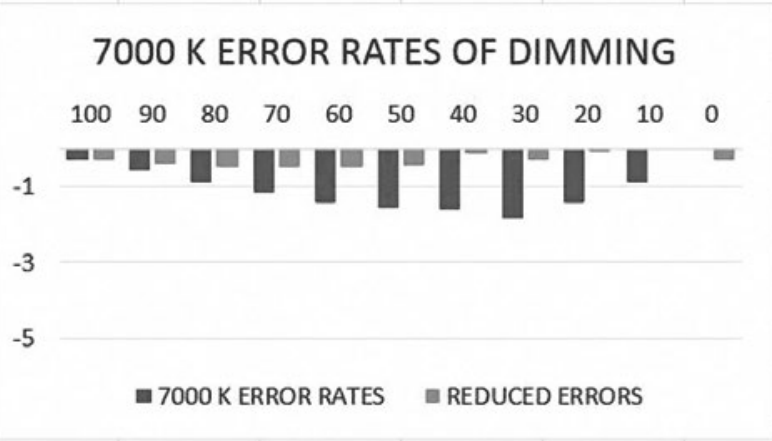

Fig.16. CCT $7000 \mathrm{~K}$ difference rates in dependence of dimming

Fig. 14 shows the difference ratios for CCT $7000 \mathrm{~K}$ LEDs from $0 \%$ to $100 \%$ for each dim level with $10 \%$ increase when the $2200 \mathrm{~K}$ LED is at $100 \% \mathrm{dim}$. From this graph y $=4 \mathrm{E}-10 \times 5-5 \mathrm{E}-08 \mathrm{x} 4$ $1 \mathrm{E}-05 \times 3+0.0022 \times 2-0.1121 \mathrm{x}+0.0138$ difference reduction function is obtained.

When we apply the curved functions of the polynomial structure of the $4^{\text {th }}$ and $5^{\text {th }}$ grades obtained from these graphs to the dim ratio of our mixture formula:

$$
\begin{gathered}
\operatorname{Dim} 1 F i x=3 \cdot 10^{-8} \cdot \operatorname{Dim} 1^{4}-10^{-6} \cdot \operatorname{Dim} 1^{3}- \\
-0.0009 \cdot \operatorname{Dim} 1^{2}+0.0689 \cdot \operatorname{Dim} 1-0.1436 \\
\operatorname{Dim} 2 F i x=4 \cdot 10^{-10} \cdot \operatorname{Dim} 2^{5}-5 \cdot 10^{-8} \times \\
\times \operatorname{Dim} 2^{4}-10^{-5} \cdot \operatorname{Dim} 2^{3}+0.0022 \cdot \operatorname{Dim} 2^{2}- \\
-0.1121 \cdot \operatorname{Dim} 2+0.0138 . \\
M(\lambda)=\operatorname{Dim} 1 F i x \times W(\lambda)+ \\
+\operatorname{Dim} 2 F i x \times C(\lambda),
\end{gathered}
$$

we get the final mixture formula.

After applying the difference reduction functions to the main formula, the differences rates have changed by decreasing as seen in the graphs (Figs. 15-16). 


\section{CONCLUSIONS \& DISCUSSION}

In order to calculate the mixture colour, it is possible to apply the side sum method of wavelengths we have used here for more than one colour. What we initially need for this is only the spectral data of the primary colours. Using the spectral data of the main colours, we can calculate the CCT of the mixture and the spectral data of the mixture colour by mixing the desired number of different colours mathematically. When we place our mixing ratios as a Dim coefficient before the spectral data of each colour in the total formula:

$$
\begin{gathered}
\operatorname{Mix}(\lambda)=\operatorname{Dim} 1 \times \operatorname{Colour} 1(\lambda)+\operatorname{Dim} 2 \times \\
\times \operatorname{Colour} 2(\lambda)+\ldots+\operatorname{Dim} N \times \operatorname{ColourN}(\lambda),
\end{gathered}
$$

and compare the results of the calculations from the software with the measured values again, they are significantly improved and reduced to less than $\pm 0.5 \%$, especially at the difference rate of $30 \%, 40 \%, 50 \%, 60 \% \mathrm{dim}$.

\section{ACKNOWLEDGEMENTS}

The author would like to thank "The Scientific and Technological Research Council of Turkey
(TUBITAK)" for funding the research project with Nr: 3140764 "Biodynamic Lighting Systems Design", which supports this work.

Our unforgettable thanks to the LITPA for funding the research project with Nr: 3140764 "Biodynamic Lighting Systems Design" which supports this work.

The author would like to thank Ms. Deniz Yuce "R\&D and Marketing Project Director" of LITPA for their valuable contributions to the present study.

The author would like to also thank University of Kocaeli for their valuable contributions to the present study.

\section{REFERENCES}

1. CIE Publication: Color-matching functions for CIE2 ${ }^{\circ}$ Standard Observer (1931).

2. CIE Publication,1932. Commission Internationale de l'Éclairage Proceedings, 1931. Cambridge: Cambridge University Press.

3. CIE15:2004 3rd Edition - CIE Standars on Colorimetry.

4. McCamy, C. S. 1992. Correlated Colour Temperature as an Explicit Function of Chromaticity Coordinates, Colour Research \& Application 17:142-14.
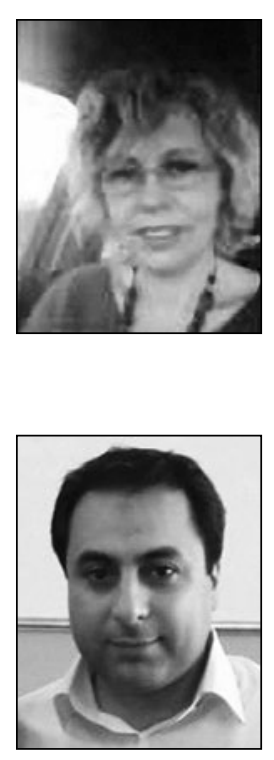

\section{Canan Perdahci}

received the B.E. and M. Sc. degrees in electrical engineering from the University of Yildiz, Istanbul, Turkey, in 1991 and 1993 respectively and the Ph.D. degree in electrical engineering from the University of Kocaeli, in 1997.

In 1992, she joined the Department of Electrical Engineering as a Lecturer and. in 1998, became an Asisstant Professor. Her current research interests include LED lighting, power quality, tunnel lighting, road lighting

\section{Hamdi Özkan}

received the B.D. in machine engineering from the University of Trakya, Edirne, Turkey, in 2003. In 2007, he joined the Production Department of Litpa Lighting as a machine engineer, and in 2003 became a Responsible of Research \& Development Department. His current research interests include mechanical and optic design of the luminaires and spectral structure of the light 